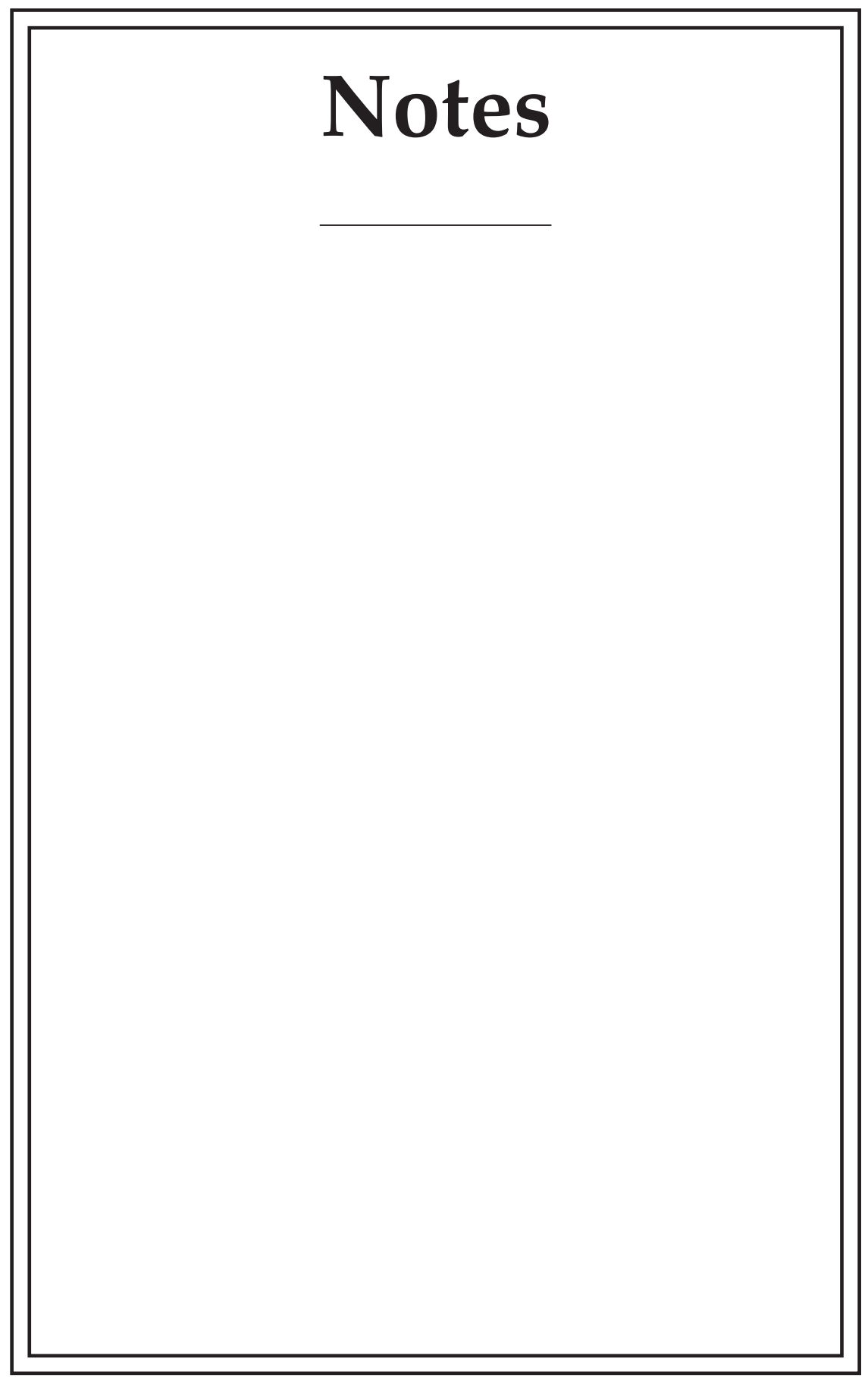

Downloaded from Brill.comఠ4/26/2023 09:10:33AM 
Basil Lourié

St. Petersburg

hieromonk@gmail.com

\title{
BETWEEN BABYLONIA AND ETHIOPIA: \\ SOME THOUGHTS ABOUT A RECENT BOOK ON THE QUMRANIC CALENDARS
}

\author{
Jonathan BeN-Dov, Head of All Years. Astronomy and Calen- \\ dars at Qumran in their Ancient Context (Leiden/Boston: Brill, \\ 2008) (Studies on the Texts of the Desert of Judah, 78) xx, 331 \\ p. ISBN 9789004170889.
}

The calendric contents of the Dead Sea Scrolls are, in our time, to be found in a very strange place - somewhere between Babylonia and Ethiopia. On the one hand, their "ancient context" is accessible through a variety of Ethiopic documents representing late Jewish calendric traditions which were available in Greek in the Hellenistic epoch, but are usually irreparably lost in this language. Among the Ethiopian documents, the most important is the Ethiopic translation of the Astronomical Book $(A B)$ transmitted in 1 Enoch; second in importance is the Book of Jubilees. In addition, many short astronomical treatises mostly originally written in Gecez but following some Jewish astronomical traditions contemporary to the DSS are also very important. The repertory and analysis of this literature by Otto Neugebauer in 1979 is not yet out-of-date. ${ }^{1}$ On the other hand, there is a Babylonian background behind Jewish calendric traditions, and especially those based on the 364-day year (364DY). It was the same Otto Neugebauer, the outstanding expert on Babylonian astronomy, who opened the way in his 1981 analysis of $A B,{ }^{2}$ but the breakthrough study was produced by Matthias

(1) O. Neugebauer, Ethiopic Astronomy and Computus (Wien, 1979) (Österreichische Akademie der Wissenschaften. Phil.-hist. Kl., Sitzungsberichte, 347; Veröffentlichungen der Kommission für Geschichte der Mathematik, Naturwissenschaften und Medizin, 22); hereafter: Neugebauer 1979.

(2) O. Neugebauer, The "Astronomical" Chapters of the Ethiopic Book of Enoch (72 to 82). Translation and Commentary. With Additional Notes on the Aramaic Fragments by M. BLAck (København, 1981) (Det Kongelige Danske Videnskabernes Selskab. Matematisk-fysiske meddelelser, 40:10); reprinted as Appendix A in: M. BLACK, The Book of Enoch or I Enoch (Leiden, 1985) (Studia in Veteris Testamenti Pseudepigraphica, 7) 386-419. 
Albani in 1994. ${ }^{3}$ Unfortunately, after several important papers by Albani and his close colleague Uwe Gleßmer in the 1990s dealing in various ways with the Babylonian background of the DSS calendars, these lines of inquiry were stopped in about 2000. Quite recently, however, Jonathan Ben-Dov has picked up the baton from Matthias Albani.

Albani's success in finding a deep background for $A B$ in the Babylonian astronomical tradition was due to the publication of the full text of a Babylonian compendium, MUL.APIN ("Polar Star"), by Hermann Hunger and David Pingree in 1989. Here, the only Babylonian text implying a 364DY calendric scheme (MUL.APIN II ii 11-12) 4 appeared for the first time. It was still unavailable to Neugebauer when he was studying 1 Enoch.

The 364DY calendric tradition is the main character of Ben-Dov's book. It is an ephemeral event in the history of Babylonian scienceborn in the mind of some Babylonian astronomers on their way from the ancient 360DY calendric scheme to the $3651 / 4 \mathrm{DY}$ one, and it became the cornerstone of the liturgical calendars and cosmological thought of many Jewish communities, including that of the DSS (cf. p. 167). ${ }^{5} \mathrm{In}$ order to clarify the outlines of Ben-Dov's monograph, I have isolated its three major story lines:

1. The 364DY calendar tradition in statu nascendi, that is, in MUL. APIN and $A B$, and its place in the corresponding astronomical and cosmological theories;

(3) M. Albani, Astronomie und Schöpfungsglaube. Untersuchungen zum Astronomischen Henochbuch (Neukirchen-Vluyn, 1994) (Wissenschaftliche Monographien zum Alten und Neuen Testament, 68).

(4) H. Hunger, D. Pingree, MUL.APIN. An Astronomical Compendium in Cuneiform (Horn, 1989) (Archiv für Orientforschung, 24) 94. These two lines of MUL.APIN mention an intercalary lunar month of 30 days in 3 years caused by the difference of 10 days between the lunar year (354 days) and the calendric year; thus, the calendric year implied is the 364DY.

(5) As Ben-Dov writes, "The 364DY was developed in Mesopotamia as an improvement upon the 360-day year. In later Mesopotamian literature, the realisation dawned that even the 'corrected' number 364 fails to provide a perfect solution, itself requiring periodical corrections. Since the 364DY did not exist long in Mesopotamia after the seventh century B.C.E., rapidly being replaced by more accurate numbers, we are unable to inspect how this anomaly [the discrepancy between the ideal 360DY of the cosmological theories and the empirical 364DY. - B. L.] was handled by Babylonian astronomers. In the following centuries, however, an abundance of Jewish material was based on the same type of year" (p. 122). 
2. The 364DY calendar tradition in the Qumranic literature (again, its place in the corresponding astronomy and cosmology);

3. the Babylonian background of Jewish calendric science.

All these major topics are illustrated by numerous case studies in the monograph, sometime very detailed and often brilliant.

The 364DY calendar tradition in statu nascendi. Ben-Dov reopens this question after Albani's 1994 monograph. He is indebted to Albani in many respects but his main conclusion is different: both MUL.APIN and $A B$ were still operating by $360 \mathrm{DY}$ idealised calendric schemes while their knowledge of the 364DY scheme was limited by the necessity of following the natural order (sidereal year's length) more closely. There is no specific interest in the heptadic orders (calendric constructions based on the number seven and its multiples), no specific cosmology in either MUL.APIN or in $A B .^{6}$ The necessity of following observable events as closely as possible was vital for Babylonian science, which was always based on observation; this is not the case for its Jewish counterpart. As to the latter, throughout his book Ben-Dov reaffirms the view of earlier scholars, who stated that Jewish astronomy was not a natural science but rather sets of religiously loaded schemes. As BenDov writes, "Scientifically speaking..., whereas the Babylonian material is rightly called 'astronomy,' a large measure of the Jewish material is better identified as 'calendar science'"' (p. 276; cf. p. 181-182). ${ }^{7}$

In both MUL.APIN and $A B$, the four extra days added to the idealised 360DY scheme are cosmologically unacceptable. This fact was noted by Neugebauer only briefly (when discussing the linear zigzag

(6) In $A B$, a meagre interest in the septenary models is always limited to the lunar phenomena; cf. Ben-Dov's discussion of Albani (p. 54-55).

(7) Of course, this is not to say that in Qumran there were no astronomical observations at all. Ben-Dov does review the discussion of a mysterious Qumranic artefact commonly interpreted as a sundial. Ben-Dov accepts this view as the most probable although unproven, but argues (convincingly, I think) against Albani's and Gleßmer's interpretation of its working principle (p. 258-259 and 189). One relevant paper that escaped Ben-Dov's attention: M. Albani, U. Glessmer, It's Not a Game, It's a... a Handy (Astronomical?) Instrument! A reaction to A. Levy's interpretation of the Qumran roundel (BAR 24,4 (1998) 18-23), XB 2 (VIII) (2000) 279-283 (with some further bibliography). In his most recent paper ("The Qumran Dial: Artifact, Text, and Context," forthcoming in J. Frey et al. (eds.), Qumran and Archeology (Tübingen: Mohr Siebeck)), Ben-Dov concludes that the artefact is certainly not a sundial but its purpose remains unclear. 
function of the length of night/daylight $)^{8}$ but it is demonstrated by Ben-Dov in a very detailed way. First of all, he adds to Neugebauer's observation that the path of the sun through the twelve heavenly gates arranged in the six pairs, according to $A B$, is also regulated by the zigzag function whose Babylonian equivalent is the motion of the sun between three "paths" (sectors) of heaven: Enlil, Anu, and Ea. Each of these "paths" is equivalent to two pairs of "gates" in the Enoch astronomy. Such a cosmology implies the 360DY and not the 364DY. Ben-Dov thus supports previous scholarship in his assertion that the 364DY passages of $A B$ are a later, even if still very early, addition to a cosmological treatise implying the 360DY (p. 32-37 and 161-167).

The editorial history of the lunar theory in $A B$ is even more complicated. Its internal contradictions were pointed out by previous scholars, especially by Neugebauer. The main contradiction is that in some places, the author operates with the 354-day lunar year with alternating full and hollow lunar months (of 30 and 29 days, respectively), and in other places, he tries to harmonize the lunar motion with the sun's yearly motion through the twelve gates both in space and in time, thus operating with ideal months of 30 days. Ben-Dov supposes that 1 Enoch 74:10-16 in its original recension formulated the triennial cycle that harmonizes the lunar 354DY with the 364DY (p. 112-113, 125-129), while realising that "[t]he calculations of the triennial cycle would not have been possible had the author also wished to account for the heavenly gates" (p. 145). However, in the preserved documents, this cycle is described explicitly only in the Qumranic documents later than $A B$, starting from an "extremely simplistic" roster in 4Q317 (a sectarian document written in the so-called cryptA script designated to a restricted circle within the sect itself), without any spatial considerations (p. 145).

From his analysis of early Jewish 364DY calendar texts (AB, Aramaic Levi Document, Book of Jubilees, and several DSS), Ben-Dov concludes that initially, the main value of the four additional days was to mark the beginnings of the four seasons (p. 38-52). Ben-Dov takes his evidence from the Jewish sources because the single reference to the

(8) Neugebauer, The "Astronomical" Chapters..., 11 = Black, The Book of Enoch..., 394. Such a linear zigzag function does not take into account the four additional days, but the very linearity of such functions is a distinctive feature of Babylonian astronomy which implies that the corresponding natural events (such as the length of daylight) change continuously between the four breaking points corresponding to the solstices and the equinoxes. 
364DY in MUL.APIN is not enough to give any cultic interpretation of the four additional days. However, at one point he seems to extrapolate this early Jewish state of affairs back to Mesopotamia. ${ }^{9}$ This seems to me the most likely scenario, given that the four-season division of the year is one of the key concepts of Babylonian calendric science.

The final conclusion of this first major "story line" is of importance for the Jewish apocalyptic tradition as a whole, not only for the documents reviewed by Ben-Dov: "Although noting the possibility for correcting the 360-day ideal, the author of Mul.Apin was unable to operate his models according to a more accurate year length, an exercise which would have required a change of the entire paradigm. A similar dilemma is reflected in $\mathrm{AB}$ with respect to the triennial cycle" (p. 129). I would add that this could explain the further corruption of the twelve heavenly gates construction in such Jewish apocalyptic documents as 2 Enoch and one of the recensions of 3 Baruch (the lost original of the Slavonic version, itself already distinct from the genuine recension), where instead of the six pairs of heavenly gates one can see five gates between different sections of heaven. In 2 Enoch, the five-gate scheme is clearly dominated by the heptadic calendar calculations. ${ }^{10}$

The 364DY calendar tradition in the Qumranic literature and the Babylonian background of Jewish calendric science. Most of BenDov's achievements in his analysis of the Qumranic calendars are connected with their Mesopotamian background. This method, in BenDov's hands, turns out to be extremely powerful.

(9) "The significance of the four days at the turn of the seasons in Jubilees $<\ldots>$ locates the book [of Jubilees] along a continuous line which stretches from Mesopotamia to the Qumran calendrical scrolls" (p. 44). Ben-Dov's conclusion here is also important because it provides a strong argument against the alleged Egyptian origin of Jubilees proposed in 2003 by Liora Ravid. As BenDov rightly points out, any genuine Egyptian tradition would presuppose the three-season year instead of the four-season one (p. 44, n. 86).

(10) B. Lourié, Calendrical Elements in 2 Enoch, in: G. Boccaccini, A. Orlov (eds.), Proceedings of the Fifth Enoch Seminar, Naples, 2009 (forthcoming); IDEm, Review of A. Kulik, 3 Baruch. Greek-Slavonic Apocalypse of Baruch (Berlin-New York, 2009), Journal for the Study of the Pseudepigrapha 19 (2010) (forthcoming), and also my forthcoming paper on the calendar and the cosmology in 3 Baruch. The dates of the calendars and the cosmologies of both 2 Enoch and 3 Baruch are still to be determined. At least, 2 Enoch's calendar is older than the book itself. Thus, I would prefer to be a bit more cautious when asserting that $A B$ is "...the earlier Jewish document to include an explicit depiction of the 364DY" (p. 280). 
Especially impressive is how Ben-Dov resolved the issue of the pair of lunar phenomena that had engaged almost all of the top figures of DSS scholarship in the 1990s, immediately after the first publication of 4Q320, 4Q321, and 4Q321a in 1991 (ch. 5 "Lunar phases in the Mišmarot scrolls and late Babylonian astronomy," p. 197-244). One of these phenomena is unnamed, labeled " $\mathrm{X}$ " by modern scholars, and the other is called $d w q$. The majority opinion (established mostly by VanderKam, Gleßmer, Albani, and Abegg) interpreted $d w q$ as the new moon and $\mathrm{X}$ as the full moon, with the month beginning at full moon (p. 223). ${ }^{11}$ According to the minority opinion (established by Talmon and Knohl and shared by Wise, Horowitz, and Ben-Dov himself), X constitutes the day of the moon's complete invisibility and $d w q$ the day after the full moon, that is, the day when the moon begins to wane (p. 225-227). In his book, Ben-Dov shifts the whole discussion from Jewish to Babylonian ground, introducing as new evidence a very close parallel, lunar texts of the so-called "Lunar Three" type that became standard from about the fifth century в.c.E. These "Lunar Threes" indicated three main lunar parameters closely corresponding to the Qumran documents: (1) the number of days in the lunar month (indicated in Qumran as well, although in a somewhat different way); (2) KUR = first morning visibility of the moon at the end of the lunation = Qumranic X; and (3) NA = first moonset after sunrise, on the day following the full moon $=$ Qumranic $d w q$ (thus confirming Talmon's and Knohl's etymology of $d w q$ from the root $d q q$ "thin," that is, the day when the moon starts to become thinner). The only difference between the Qumranic "Lunar Threes" in the mišmarot texts and their Babylonian prototypes consists in the fact that the numbers in the Babylonian tables contain some variances in their figures because they were the results of empirical observations, whereas in Qumran, only rigid computational schemes are used. Nevertheless, the exactitude of the correspondence is revealing. Compare, in a Babylonian document (BM 32327, third century в.C.E.), the interval from NA to KUR, which is 13 or 14 days (occasionally 12 or 14 ) and, in $4 Q 320-321$, from $d w q$ to $X$ is always 13 days; in the

(11) Ben-Dov argues convincingly against the month beginning at the full moon in $A B$ and the Qumranic calendars, thus denying any connection with the evidence of the full moon reckoning from the medieval Maghariah sect (p. 223-227, esp. 224). It is likely, however, that Maghariah's reckoning goes back to some earlier epoch, so the question of the origin of this reckoning needs to be reopened. 
same documents, from KUR to NA is 16 or 17 days and from $\mathrm{X}$ to $d w q$ is also 16 or 17 days.

In spite of the fact that our knowledge of Babylonian astronomy has grown rapidly over the last quarter century, given its relatively brief period of development and correspondingly brief period of documentation, it is no wonder that we have missed some important Babylonian texts representing ideas accepted in the Jewish milieu. Ben-Dov points out one especially important case (p. 183-184) in which the Babylonian origin of an idea is demonstrable but, so far, without textual evidence. It is the case of the subdivision of the day (nychthemeron) into 18 "parts" (Gecez kafl, in $A B$ and many other Ethiopic astronomical treatises; the Akkadian/Sumerian equivalent is unknown, the Hebrew equivalent is מחלקת "division, part"12). As Neugebauer has pointed out, this subdivision corresponds to the scheme in which the longest day/night is divided into 12 parts and the shortest day/night into 6 parts. Such a 2:1 ratio corresponds to the Mesopotamian reality but not to the Judean one (another ancient scheme is also known: most Egyptian astronomical texts have this ratio as 3:1). The duration of the night/daylight changes according to a linear zigzag function in which monotonic periods take three months each. It is only the 18-part division of the nychthemeron for the 12-month year that provides a onepart change per month, because 18 is the smallest natural number that can be divided into twelve months in a 2:1 ratio avoiding the use of fractions, and thus permitting one to calculate the velocity of change as one "part" per month. Needless to say, this Enochic calculation is "completely detached from the actual measurement of time units" (p. 184). The 18-part subdivision makes sense in the Babylonian astronomical schemes, and so must be attributed to Babylonia.

The problem of kekros. I would add that some other concepts of traditional Ethiopian astronomy are likely candidates for Babylonian ancestry, especially kekros and kentros. The basic meaning of these terms is, respectively, $1 / 60$ and $1 / 30$ of some interval of time. Both terms, even

(12) Known from 4Q317 fr. 1, II, 11, as Jonathan Ben-Dov pointed out to me. This term is often used in 1 Chroncles in a technical sense of the organisa-

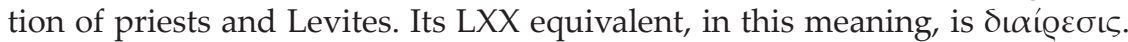
The latter recalls another Ethiopic term, kufäle, as it is used in the Ethiopian title of the Book of Jubilees ("Book of Division/Distribution"), but kafl is also

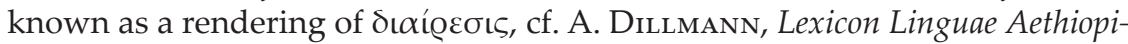
cae (Lipsiae, 1865; repr. Osnabrück, 1970), col. 878. Thus, probably, kəfl may be rendered more correctly as "division/section." 
if known exclusively from late Ethiopian astronomical treatises, can be traced in earlier sources. Setting aside the discussion of kentros, ${ }^{13}$ let us concentrate on kekros. The notion of kekros is used for designating either "in computus of the sun and the moon," $1 / 60$ of the equinoctial 12-hour day (thus, 1 kekros $=12$ minutes, 1 hour $=5$ kekroses), or "in computus of the stars," $1 / 360$ of the 24 -hour nychthemeron (thus, 1 kekros $=4$ minutes). ${ }^{14}$ In the latter sense, kekros is the same as the Babylonian $u \check{s}$, which is a unit of both time and space, a time degree, corresponding to $1^{\circ}$ of the movement of the celestial sphere, and thus to about 4 minutes. ${ }^{15}$

Neugebauer in 1979, when reporting one case of a striking identity between the Ethiopian notion of gize ("time" = double hour, 2 hours) and the Babylonian notion of bèru (2 hours), wrote: "I do not know where the concept of 'double hour' originated. A relationship to the Babylonian 1 uš $=0 ; 4^{\mathrm{h}}-1$ bēru $=2^{\mathrm{h}}$ seems to me unlikely." ${ }^{16}$

It seems not so unlikely now, when we have a better understanding of some Jewish links between the Babylonian and the Ethiopian astronomies. In the passage just referred to, Neugebauer quotes from

(13) Neugebauer 1979, 169, supported by Albani, thought that an Aramaic $A B$ fragment 4Q211 meant the kentros (here 1/30 of a "part"). Ben-Dov quotes both of them favourably, adding that this fragment "...clearly forms part of the Mul.Apin-type astronomical teaching" (p. 195). However, Ben-Dov mistakenly names kentros as "kekros" in this passage. The notion of kentros occurs in different contexts (where it means 1/30 of different units of time) but, in general, its origin remains obscure (cf. Neugebauer 1979, 177-178). Nevertheless, its origin within a MUL.APIN-type astronomical context now seems demonstrated with a high degree of probability. Its etymology from

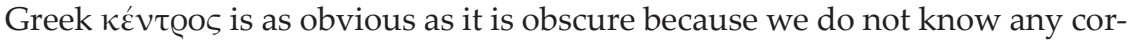
responding terminological meaning in Greek (s. Neugebauer 1979, 175).

(14) Neugebauer 1979, 176-177.

(15) Here my formulation is a bit anachronistic. It fits completely the ava-

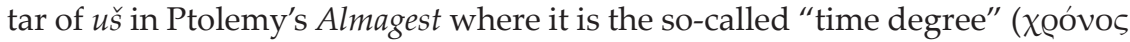

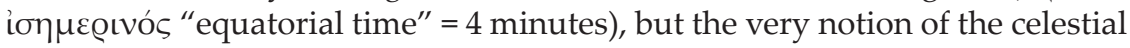
sphere is much later than the notion of $u \check{s}$, and even the existence of such a concept in the Babylonian cosmology is an open question. Babylonian $u \check{s}$ emerged from the water-clock measurements in which the amount of water used was not dependent on the season. See F. R. Stephenson, L. J. Fatooni, The Babylonian Unit of Time, Journal for the History of Astronomy 25 (1994) 99-110.

(16) Neugebauer 1979, 168. Here $0 ; 4$ is a sexagesimal fraction, $4 / 60$ of hour $=4$ minutes. 
a manuscript the relationship 1 gize $=10$ kekroses (according to the "computus of the sun and the moon," as we now know), but does not take into account the "computus of the stars" where kekros becomes an equivalent of $u \check{s}$, that is, a very peculiar element of Babylonian astronomy connecting the measurement of time with the daily motion of the sun. ${ }^{17}$

This supposition opens a way to reconsider the etymology of the term kekros (sometimes written as kikros). Although the existence of some Greek prototype is not in doubt here, it is not obvious. August Dillmann's early etymological attempt (1865) was severely rejected by Neugebauer ("The naïve etymology kēkros = circus [i.e., through кíкоৎ] is not worth discussion beyond remarking that nowhere in ancient astronomy does circus appear as a technical term"18), although without supplying any alternative. Given that the Greek texts that were mediators between the Enochic astronomy and Ethiopia are lost almost completely, it is no wonder that some terms are lost in Greek. Most often, the corresponding words are known in Greek, but not in the terminological sense (such is the situation of kentros). If a term was a loanword used in the terminological sense only, it had to disappear completely, with no trace in Greek sources. Thus, it is reasonable to ask whether the Ethiopic kekros goes back to a lost loanword in Greek, ${ }^{*} \kappa \varepsilon ́ \kappa \varrho O \zeta$. In this case, the most natural source language is Akkadian.

(17) A possible Babylonian origin of kekros waives one of Ben-Dov's objections to Neugebauer's explanation of the apparent contradiction between 1 Enoch 79:10-11 (operating with the 360DY, while with a mention of the number 364 in 79:10b as probably a later correction) and 79:13-16 (operating with the 364DY). According to Neugebauer, vv. 10-11 mean "days" as 1/360 of the sidereal year where these sexagesimal "days" are analogous to the kekroses according to the "computus of the stars" (Neugebauer 1979, 231). Ben-Dov's objection to this, that "...the concept of kekros... originates from significantly later literature" (p. 126, n. 18), does not hold. Nevertheless, I accept Ben-Dov's explanation of the contradiction (that it is due to the difficult redaction story of $A B$ ) as simply the most natural. Neither $A B$ nor MUL.APIN were consistent in dealing with the 364DY astronomy.

(18) Neugebauer 1979, 175. Leslau adds nothing to this reference to Neugebauer except his erroneous statement that kekros means "interval of twentyfour minutes" [W. Leslau, Comparative Dictionary of Gecez (Classical Ethiopic) (Wiesbaden, 1987) 280-281, s. v.]. Siegbert Uhlig repeats Dillmann's etymology in the same place where he quotes Neugebauer, but fails to mention Neugebauer's criticism [S. Uhlig, Chronography, in: S. Uhlig (ed.), Encyclopaedia Aethiopica, vol. I (Wiesbaden, 2003) 733-737, here 737]. 
Indeed, in Akkadian, we have the word kakkaru that has a terminological meaning of "metal disk ${ }^{19}$ (weighing one talent)," the latter being a weight unit equal to 60 minas or 6000 shekels. ${ }^{20}$ Mina (manu) is the sixtieth part of talent (biltu) as a weight unit or, as a time unit, the weight of water running through a water clock over $1 / 6$ of the nychthemeron (= 4 hours). Another meaning of man $\hat{u}$ as a time-space unit is $6 u s ̌$ (biltu is unknown in the time-space meaning at all). ${ }^{21}$ The latter meaning of man $\hat{u}$ is the most interesting to us: $6 u \check{s}=24$ minutes $=1 / 60$ of nychthemeron. We see here the same principle of the sexagesimal subdivision of the day as in the Ethiopic kekros (with the only distinction that its application to the whole nychthemeron is unknown in Ethiopia).

Both biltu and kakkaru are unattested in the spatiotemporal meaning but, unlike biltu, kakkaru always signifies round or circle, even if it is a unit of weight. Thus, manû as one-sixtieth of kakkaru is one-sixtieth of a circle, while man $\hat{u}$ as one-sixtieth of biltu is simply one-sixtieth of a mass unit. On the other hand, there is an attested meaning of man $\hat{u}$ where it is one-sixtieth of the nychthemeron, which is one of the cycles (circles) of time. This is why I consider the existence of a spatiotemporal meaning of kakkaru very likely. As a spatiotemporal unit, kakkaru would mean the sum of sixty fractions, especially the nychthemeron when considered for sexagesimal partition. This meaning is already very close to that of the Ethiopic kekros (the main difference is that kekros is itself a sexagesimal part and not the sum of all such parts). In the word kekros, the Greek ending -os replaces its original Akkadian ending. Otherwise, the Akkadian term is preserved quite well: kakkaru>

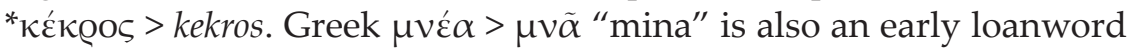
from Akkadian borrowed together with its sexagesimal relationship to the talent. ${ }^{22}$ "Talent" is an Indo-European word that replaced, in

(19) Other meanings of kakkaru as well as its root meaning are also connected with "disc" or "circle." In this way, probably, Dillmann was right in his etymology of kekros from circus, while only on the remote level of the Afrasian and Indo-European linguistic unity.

(20) The Assyrian Dictionary of the Oriental Institute of the University of Chicago. Vol. 8: K (Chicago-Glückstadt, 1971) [thereafter: CAD with the title (letter) of volume and page numbers] 49-50, s. $v$.

(21) CAD M, 220-221. Cf. CAD B, 229-236, s. v. biltu.

(22) The corresponding Semitic root is attested in different Semitic languages, cf. Hebrew mānē, Ugaritic mn, Phoenician (Szemerényi's reconstruction) *manē [see P. Chantraine, Dictionnaire étymologique de la langue grecque. Histoire des mots (Paris, 1968-1980) 707; H. FRISK, Griechisches etymologisches 
Greek, the original Akkadian term for a unit equal to 60 minas, that is, either biltu or kakkaru. It is likely that one of the latter words or even both were borrowed, too, although they later fell out of use.

It is kakkaru that was borrowed by Aramaic (different dialects, from Official Aramaic to Syriac) in two forms, $k k r$ and $k n k r$ (with dissimilation of geminants), and with two meanings, "talent" (mass unit) and "loaf" ${ }^{23}$ (round piece of bread, etc.; the same also in Akkadian). The form $k k r$ might become an Aramaic intermediary between Akkadian kakkaru and Greek ${ }^{*} \kappa \varepsilon ́ k 00 \varsigma,{ }^{24}$ although such an intermediary is not necessary (and we do not know whether early Aramaic $k k r$ presupposed any sexagesimal partition ${ }^{25}$ ).

At any rate, the Akkadian kakkaru is to be recognised in a strange Ethiopic word of Greek origin, kekros. Thus, it seems to me that in Greek, $\mu \nu \tilde{\alpha}$ and ${ }^{*} \kappa \varepsilon ́ \kappa \varrho O \varsigma$ were sometime connected to each other in the same manner as, in Akkadian, man $\hat{u}$ and kakkaru.

Origin of the twelve heavenly gates in $A B$. Despite the fact that $A B$ is a treatise along the same lines as the MUL.APIN astronomy, its twelve heavenly gates are known nowhere in the extant Babylonian texts. ${ }^{26}$ In the Babylonian tradition, two prerequisites of this concept

Wörterbuch, Bd. II (Heidelberg, 1970) 247]. However, for Akkadian or Sumerian as the source language, see É. Masson, Recherches sur les plus anciens emprunts sémitiques en grec (Paris, 1967) (Études et commentaires, 47) 32-34 (cf. Frisk, Griechisches etymologisches Wörterbuch, Bd. III (1972) 153); W. BurkerT, Orientalizing Revolution. Near Eastern Influence on Greek Culture in the Early Archaic Age (Cambridge, MA-London, 1992) (Revealing antiquity, 5) 37, 175. Borrowing is dated to the post-Mycenaean period (after $c a 1100$ в.с.E.) because in the Mycenaean epoch, whose system of measures and weights is well known, there are no traces of either mina or sexagesimal fractions of the talent.

(23) According to the Comprehensive Aramaic Lexicon (http://cal1.cn.huc. edu/).

(24) I am grateful for this idea to A. N. Duntsov. Edward Lipiński provides

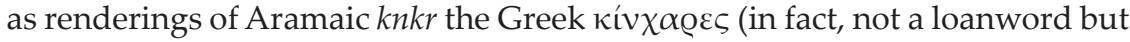
rather an ad hoc transliteration in Josephus, Ant 3:144) and the Coptic ğinğōr, ğinğor [E. Lipı́́sKI, Semitic Languages: Outline of a Comparative Grammar (Leuven, 1997) (Orientalia Lovaniensia Analecta, 80) 176)].

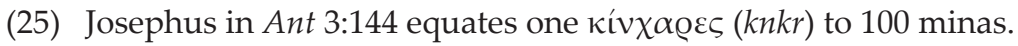

(26) As Ben-Dov writes, "The concept of twelve gates remains unique in the history of astronomy, continuing solely in trajectories of AB: Slavonic Enoch, Ethiopic astronomy, and a Persian-Sogdian text which, according to Tubach, is dependent on 1 Enoch 72 [i.e., Manichean fragments published by J. Tubach in 1986]" (p. 185). The Slavonic Enoch does not contain the concept 
were firmly established: (1) use of the sections of the horizon to describe phenomena concerning the entire $\mathrm{sky},{ }^{27}$ and (2) the very concept of the heavenly gates (abullu = ideographic KÁ.GAL) used by luminaries and all other objects (including men) ascending the heaven, especially when it is specified that the gates form symmetrical pairs on the two sides of the horizon (such as the "gateways in both ribcages (sillī)" of heaven). ${ }^{28}$

To explain the origin of the six pairs of symmetrical heavenly gates, Ben-Dov evokes an "analogy" (p. 185) that he considers to be only typological, with no direct genetic relationship: Ptolemy, Harmonica, 3.12. ${ }^{29}$ Here, Ptolemy establishes a direct relation between the modulations of the seven tonoi (modes) and the harmony of the heavenly spheres. Unlike $A B$, however, he employs the concept of the heavenly sphere (Fig. 1). Ptolemy gives a clear idea how the ecliptic divided into twelve parts by the zodiacal constellations can be projected to the horizon, making two symmetrical rows of six arcs. The sun traces out the ecliptic eastward (in the opposite direction of the sun's daily motion),

of twelve gates: here, the number of the gates is only five and their function is very different; see Lourié, Calendrical Elements in 2 Enoch.

(27) Here, Ben-Dov quotes E. Reiner and D. Pingree (in their edition of another Babylonian work in the MUL.APIN-type tradition, the Enüma Anu Enlil, tablets 50-51 (1983)) that three "paths" of heaven "...most commonly signify sections of the horizon rather than a division of the entire sky" (p. 163, Ben-Dov's wording).

(28) Enuma Eliš V, 9-11. See esp. W. Heimpel, The Sun at Night and the Doors of Heaven in Babylonian Texts, Journal of Cuneiform Studies 38 (1986) 127-151, esp. 134. Ben-Dov does not take into account any Babylonian background of the "gates of heaven," and thus creates difficulties for himself when investigating the origin of the Enochic twelve-gate concept (see below).

(29) "We are not asserting here that $\mathrm{AB}$ was associated in any sense with Ptolemy, merely that the Ptolemaic scheme constitutes a useful analogue for the system of twelve gates-or, more substantially, the division of the horizon into six bands" (p. 186). For a new critical edition and commentaries of the Harmonica, see the thesis of Pedro Redondo Reyes, La Harmónica de Claudio Ptolomeo: edición crítica con introducción, traducción y comentario (Murcia: Servicio de Publicaciones. Universidad de Murcia, 2002), here 121-122 (txt), 256-257 (tr.), 767-768 (notes). The graphic schemes that are usually employed to illustrate the relevant passage of Ptolemy (reproduced by Ben-Dov, p. 186, fig. 4.2) would be anachronistic in relation to $A B$. They presuppose the notions of the celestial sphere and the celestial equator, both of them alien to $\mathrm{AB}$ and MUL.APIN; the celestial equator is unknown to Babylonian astronomy in any fashion (see Fig. 2). 


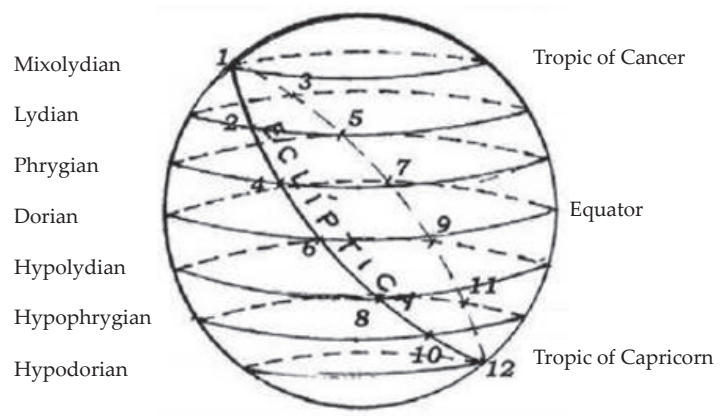

Figure 1. Ptolemy's harmony

between the seven musical modes and the twelve signs of the zodiac

(adapted from Reyes, La Harmónica de Claudio Ptolomeo..., 768).

Signs of the zodiac: Cancer (1), Gemini and Leo (2 and 3), Taurus and Virgo (4 and 5), Aries and Libra (6 and 7), Pisces and Scorpio (8 and 9),

Aquarius and Sagittarius (10 and 11), Capricorn (12).

On the diagram, the arcs of the horizon are shown as having equal length, while the arcs of the ecliptic are of different length; in reality (here, the reality of the Ptolemaic geocentric system), it is quite the opposite.

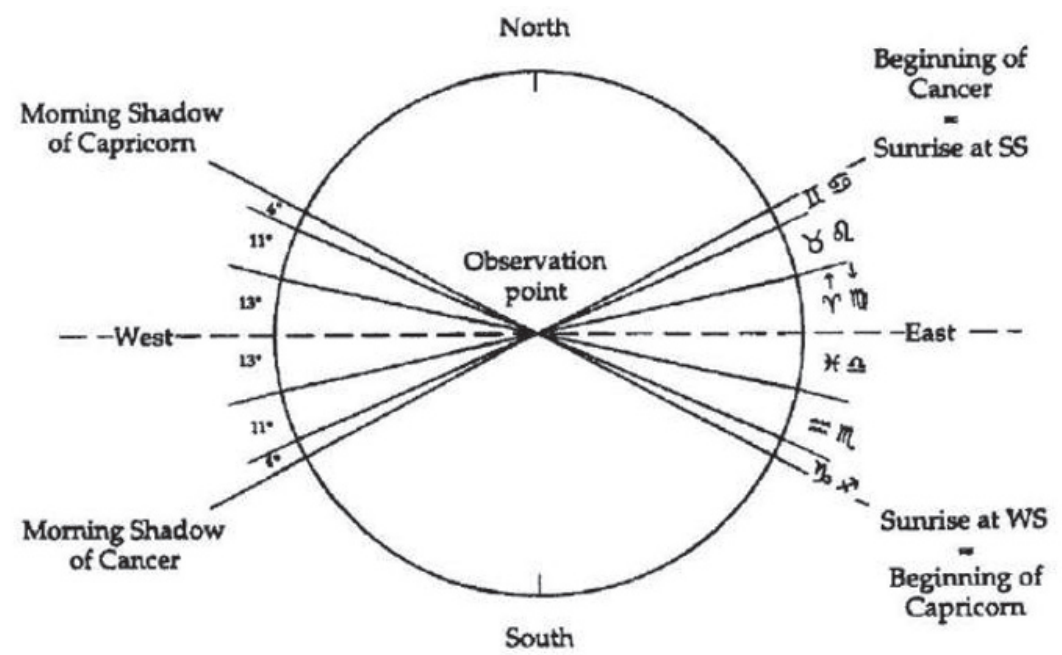

Figure 2. The observable projections

of the twelve zodiacal parts of the ecliptic to the horizon

(based on the supposition that the beginning of the horizontal arc of Cancer coincides with the sunrise point at the summer solstice).

From Brack-Bernsen, Hunger, The Babylonian Zodiac..., 284, fig. 1.

Cf. ibid., fig. 2 (based on the supposition that sunrise at the summer solstice is on the middle of Cancer) where the arcs of the horizon are of even greater difference in length. 
with the highest rising point on the summer solstice in the sign of Cancer and the lowest point on the winter solstice in the sign of Capricorn. These extreme points are symmetrical in relation to the heavenly equator and correspond to the symmetrical circles on the heavenly sphere called tropics. Ten remaining signs of the zodiac form five pairs, each defining a planar section of the heavenly sphere (the pair of Aries and Libra corresponds to the plane of the heavenly equator and to the two equinoxes). Thus, the part of the heavenly sphere between the latitudes of the two tropics is sliced by the five planes into six discs of unequal thickness (the ecliptic is divided into the twelve equal arcs, and so, given that the length of the arc is always the same, their projections to the horizon will be arcs of different length - because of the inclination of the equator to the ecliptic at an angle of $23.5^{\circ}$ ).

In his comparison of $A B$ and this Ptolemaic harmony, Ben-Dov concludes: "...the Enochic author who produced the system of gates may have been aware of the zodiacal signs. For some reason, however, he chose not to refer to them explicitly but rather adopt a system which reflects the ecliptical orbits of the sun and moon only obliquely, referring solely to their position on the horizon. This notion was part of the general tendency in $A B$, where the focus of celestial activity appears to be the horizon rather than the ecliptic." Ben-Dov then refers to 4Q318 (an Aramaic brontologion operating with the signs of zodiac) as a later document that, in contrast, sets out the ecliptical positions of the moon, thus moving away from the Enochic astronomy tradition (p. 187). Indeed, $4 \mathrm{Q} 318$ is a document of Hellenistic astronomy (astrology) while $A B$ represents an older Babylonian tradition whose difference from the latter is often partially overlooked. It is this difference that could explain "some reason" why neither $A B$ nor the whole MUL. APIN-type astronomical tradition uses the concept of the ecliptic.

By definition, the ecliptic is the trajectory of the sun on the sphere of the fixed stars. However, in the MUL.APIN universe, neither such a sphere nor such stars exist. When one speaks about the "fixed stars" in Babylonian astronomy, one would say that these stars are indeed fixed in the sense that they do not participate in the yearly movement of the sun eastward; this movement can thus be measured in relation to their positions. However, these "fixed" stars are not fixed themselves in the literal sense of the Ptolemaic geocentric system. All the luminaries, without exception, arise above the flat earth (not the spherical earth of Ptolemy) passing from the specific heavenly gates. What they do when they are invisible, somewhere beyond the horizon, in the "interior of 
heaven" (ú-tu-ul šamê) is not so clear. There are somewhat contradictory accounts. ${ }^{30}$ Be that as it may, the Babylonians did not have any room for the concept of the path of the sun among the fixed stars. Instead of following such a path, the sun rises every day in the same manner as these stars rise every night. Only at the moment of the heliacal rising (the first star's rising on the eastern horizon before sunrise, after the period of the star's invisibility) can one see that the "fixed" constellations gradually (with an angular velocity of about $1^{\circ}$ per day) replace each other. The moments of appearance and disappearance of a given luminary did have, naturally, a basic value for such astronomy. This is not to say that the Babylonians were unaware of the zodiac, even if MUL.APIN still uses seventeen constellations to locate heavenly bodies on the sky. By the fifth century в.С.E., their number was reduced to twelve, restricted to the now usual list of the zodiacal constellations. ${ }^{31}$ The distribution of the twelve zodiacal areas within the twelve equal zones of $30^{\circ}$ was performed shortly before 400 в.с.Е. ${ }^{32}$

Lis Brack-Bernsen and Hermann Hunger put forward the hypothesis that the zodiac was invented in Babylonia by the observation of the luminaries in relation to their appearance above the horizon, in such a way that not the ecliptic but the arcs of horizon were used as limits for each of the twelve zodiacal areas (see Fig. 2). Brack-Bernsen and Hunger themselves pointed out the resemblance of such a system to the heavenly gates in $A B$ (see Fig. 3). ${ }^{33}$

The unevenness of the length of the horizontal arcs does not contradict the strict correspondence of one month (30 days) to one zodiacal sign in Babylonia or the equal length (30 days in the 360DY idealised scheme) of the periods of the sun's rising from a given gate in $A B$. In the Babylonian documents, there is no statement that the sun moves

(30) See, for details, Heimpel, The Sun at Night and the Doors of Heaven...

(31) F. Rochberg, The Heavenly Writing: Divination, Horoscopy, and Astronomy in Mesopotamian Culture (Cambridge, 2004) 130.

(32) Thus according to L. Brack-Bernsen, H. Hunger, The Babylonian Zodiac: Speculations on its invention and significance, Centaurus 41 (1999) 280-292, here 280. See also, especially for the pre-history of the zodiac: В. В. Емельянов, Ниппурский календарь и ранняя история зодиака [V. V. ЕмеL'JAnov, The Nippur Calendar and the Early History of the Zodiac] (St Petersburg, 1999) (Orientalia).

(33) Brack-Bernsen, Hunger, The Babylonian Zodiac...; for comparison with $A B$, see p. 283. Ben-Dov does mention this paper (p. 257, n. 27) but does not use it in his analysis of $A B$. 
with a uniform velocity. ${ }^{34}$ Let us add that there is no such statement in $A B$ either. If the sun's velocity in relation to the horizon is changeable from one arc to another, there is no problem with establishing the equality of the time intervals for the sun's passing across each arc.

Moreover, Brack-Bernsen and Hunger noticed that their hypothesis could explain a mysterious expression in $A B$ (1 Enoch 72:6), where the fourth gate is called the "great gate." 35 Indeed, the greatest gates are around the equinoxes, ${ }^{36}$ that is, the fourth (corresponding to the beginning of the year) and the third. To pass the greater gate does not demand more time than to pass any other. This is explainable by the uneven velocity of the sun in the gates.

The remark of the Enochic author calling the fourth gate "great" without giving any further explanation appears to be an implicit reference to an already-established tradition (unless we suppose a lacuna in the available text). In any case, in Babylonian astronomy, all the prerequisites for the twelve-gate cosmology were ready: (1) connecting the sky observation data to the arcs of horizon; (2) the concept of the heavenly gates; and (3) the idea of symmetrical gates in "both ribcages" of heaven (cf. Enuma Eliš quoted above).

Thus, I consider the twelve-gate cosmology as, most probably, a borrowing from a presently unknown Babylonian source. It seems to me extremely unlikely that it was an invention by the Enochic author, who does not appear to have been a very creative or gifted astronomer.

Heavenly gates for every day. Ben-Dov proposes an interpretation of the cosmology implied in the Qumranic papyrus 4Q503 papDaily Prayers - unfortunately, a very fragmentary text (p. 132-139). He concludes "that in 4Q503 each daily exit of the sun is counted as one 'gate'" (p. 135). These gates are, of course, different from the gates in $A B$. This reconstruction could be corroborated by a part of the tradition of 3 Baruch 6:13, where "365 heavenly gates" are mentioned (Greek recension only; however, the reading of the majority of Slavonic mss as "65" is, according to scholarly consensus, a corruption of "365"). In

(34) Brack-Bernsen, Hunger, The Babylonian Zodiac..., 289.

(35) Neugebauer was perplexed by this verse. In his commentary, he asked: "Why is gate 4 called "large"? Dillmann thinks of a comparison with the windows which eject flames $(72,7)$. Are other gates not provided with such windows?" (Neugebauer, The "Astronomical" Chapters..., 12). Indeed, to have windows does not mean to be "large."

(36) Brack-Bernsen, Hunger, The Babylonian Zodiac..., 292, n. 4. 


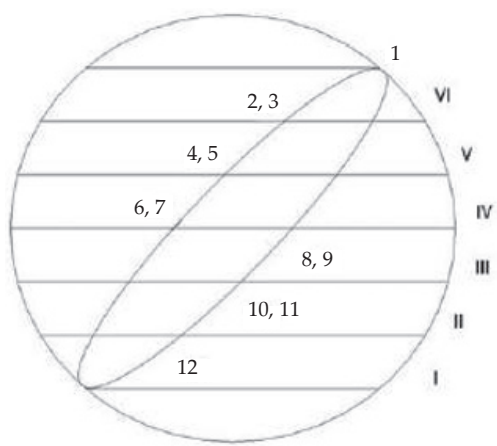

Figure 3. The idealised projection of the ecliptic to the horizon: the northern point of the ecliptic corresponds to the tropic of Cancer, the southern point to the tropic of Capricorn.

The sections located between the two tropics are divided by the five lines, each of which is defined by one pair of the signs of the zodiac (numbered as in Fig. 1). All six branches of heaven are presented as equal in width, notwithstanding the observable data. Roman numerals from I to VI correspond to the six gates of the East (the six gates of the West are those on the opposite side of the horizon).

3 Baruch the number "365" refers to the 365DY which is here a later modification. ${ }^{37}$ Nevertheless, the idea of a specific gate for each day is explicit in 3 Baruch.

Septenary principle. Neither Babylonian astronomy nor Babylonian liturgics is considered to be especially interested in septenary constructs (even if the sacred nature of the number seven is traceable in Babylonian mythology). Ben-Dov convincingly argues (pace Albani) that $A B$ is similarly uninterested in such constructs. The Jewish "sacred arithmetic" (Ben-Dov's bon mot, p. 151) based on the number seven and its multiples is a later idea replacing the observation-based Babylonian astronomy. "While the 364DY was not created as a septenary construct, it was easily identified as such and consequently adopted and developed in various apocalyptic circles," Ben-Dov writes (p. 59). It appears that the septenary principle replaced observation when Babylonian astronomy was transplanted to Jewish soil.

(37) Lourié, Review of A. Kulik, 3 Baruch. Here I disagree with Kulik, who argues for the 365DY as the genuine one. For a detailed review of the one-gate-per-day cosmological tradition, see A. KuLIK, 3 Baruch. Greek-Slavonic Apocalypse of Baruch (Berlin-New York, 2009) 257-259; his main witnesses are y. Rosh. HaSh. 2.58a, Pirqe R. El. 5, and the Iranian Bundahišn 5 B 3-6. 
We now have documentary data suggesting that the reality was a bit more complicated. In a recently published text, BM 54312 (Neo- or Late Babylonian tablet, ca 1000-539 в.с.є.), a liturgical commentary on the Akitu-festival, ${ }^{38}$ the role of the number seven is somewhat surprising. Normally, the corresponding ritual, being a New Year ceremony, occupies the first eleven days of the year, from Nisannu 1 to $11 .{ }^{39} \mathrm{In}$ BM 54312, however, these days are reduced to seven, from 5 to 11 (thus, even Nisannu 1 is excluded from the New Year festival). The main subject of the ritual must adorn himself in the following manner (italics for seven and its multiple fourteen are mine):

(a) seven waistbands;

(b) fourteen writing styli of reed, seven strapped at his right side, seven at his left;

(c) two more styli, two at the front and two at the back;

(d) two upper overgarments and two lower overgarments;

(e) belts, evidently two in number;

(f) an unidentified item (text damaged) worn behind the waist;

(g) fourteen twists of coloured wool, seven on the right and seven on the left;

(h) another unidentified item, made of linen;

(i) headgear? ${ }^{40}$

Such a heavy emphasis on the number seven is unusual for Babylonian rituals. It is certainly tied to the modification of the liturgical calendar where the number of days of the festival is reduced to seven.

(38) A. R. George, Babylonian Texts from the Folios of Sydney Smith. Part Three: A Commentary on a Ritual of the Month Nisan, in: A. K. Guinan et al. (eds.), If a Man Build a Joyful House: Assyriological Studies in Honor of Erle Verdun Leichty (Leiden-Boston, 2006) (Cuneiform Monographs, 31) 173-185. Cf. further on this text: B. В. Емельянов, Новые источники по месопотамскому культовому календарю [New Sources on the Mesopotamian Cultic Calendar], Вестник древней истории (2009) № 1, 236-243. I am grateful to Vladimir Emel'janov for drawing my attention to these and other relevant publications.

(39) This festival could be closely connected to some of the Jewish 364DY calendar traditions. The calendar of 2 Enoch starts its liturgical year on 11.I (at least, according to my reconstruction; Lourié, Calendrical Elements in 2 Enoch). Jonathan Ben-Dov pointed out to me that even in the usual Akitufestival, the four first days are only days of preparation.

(40) George, Babylonian Texts..., 178. 
Thus, we have here a Babylonian precedent of the Jewish manner of arranging the liturgical calendar according to the septenary principle. Although Jewish astronomy developed from Babylonian practice, given the short lifetime of the latter it is no wonder that the Babylonian sources are so often difficult to trace and discovered only by chance. It seems to me most likely that even the Jewish septenary principle was initially a part of the Babylonian legacy in Jewish astronomy.

Divine covenant with the heavenly luminaries. The passages in $4 \mathrm{Q} 319$ and $4 \mathrm{Q} 320$ presenting the mišmarot cycle as a fundamental element of creation reminded Ben-Dov of the passage of the Enüma Eliš tablet $\mathrm{V}$, where a "covenant" terminology is used in relation to the luminaries. Ben-Dov recalls Landsberger's and Wilson's observation (1961) that the word riksu $(\mathrm{V}, 6)$ is taken "to convey more a legal implication or obligation or duty, rather than the notion of course, revolution [sc., of the luminaries]" (p. 277 and n. 96). Vladimir Emel'janov drew my attention to the fact that riksu also has the meaning of "ritual." Indeed, the covenant symbolism would presuppose a ritual. BenDov goes further and translates line $\mathrm{V}, 7$, ana là èpiš anni lā egû manāma, as "so that (they will) not commit sin nor loosen in any way" (p. 277, n. 96) ${ }^{41}$ Ben-Dov's approach is corroborated by the meaning of another key term in the same passage $(\mathrm{V}, 6)$, Neberu. ${ }^{42} \mathrm{I}$ argue elsewhere that this is a designation of a heavenly "ford" between different "paths" of heaven (Ea, Anu, and Enlil), analogous to the inter-heavenly "gates" in some part of the Jewish apocalyptic tradition (3 Baruch, 2 Enoch). Passing through such a ford has a ritual connotation of entering into

(41) This translation seems to be the most literal and the most helpful in explaining the real meaning of the text. If the luminaries are in a sort of covenant, they must be - theoretically - able to commit sin. The Russian scholarly translation of Gennady Kurtik shares this interpretation (ēpiš anni= "commit $\left.\sin ^{\prime}\right)$ : “[ч]тобы никто (при своем движении) не совершил греха иди не проявия неряшливость" [Г. Е. Куртик, Звездное небо древней Месопотамии. Шумеро-аккадские названия созвездий и других светил [The Star Heaven of Ancient Mesopotamia: the Sumero-Akkadian Names of Constellations and Other Heavenly Bodies] (St Petersburg, 2007) 368]. Cf. some previous scholarly translations: "that none (of the stars) should make a mistake (or) not be on time" (CAD E, p. 203, s. v. epēšu 2c s. v. arnu (annu)); "And that none (in their movement) should err or be remiss" (B. LANDSBerger, J. V. K. Wilson, The Fifth Tablet of Enuma Eliš, Journal of Near Eastern Studies 20 (1961) 154-179, here 157).

(42) "He fixed the stand of dNeberu to determine their ritual arrangements"; here I translate riksu as "ritual arrangements" (cf. CAD R, 351-352, s.v. riksu 5). For Neberu, see now Куртик, Звездное небо..., 367-370. 
covenant, as it is in the related Hebrew root ${ }^{c} b r$, "to pass through/to enter into covenant." 43

Conclusion. The most impressive element in Ben-Dov's book is probably the feeling of the extreme proximity of the Jewish 364DY tradition to the Babylonian one. My notes above are intended only to reenforce such an impression. The contacts were established not between the peripheries but "...directly between the heart of one tradition and the heart of another," writes Ben-Dov, quoting Peter Kingsley (1992) (p. 246). "Since this scholarly discipline... was considered secret and esoteric in Babylonia itself, the Jewish scholars who borrowed it evidently had access to the very heart of the scholarly institution" (p. 245-246). The corresponding phase of Babylonian astronomy is datable to "a short period around 700 в.с.Е.," the date of the final redaction of MUL.APIN (p. 246).

When did the close contacts between Jewish and Babylonian scholars first take place? Ben-Dov thinks they occurred during the long period from $\mathrm{ca} 700$ to the date of $A B$ (dated variously from the midthird century to the Persian period up to $c a 400$ в.C.E.), but especially and quite naturally - the period of Babylonian exile in the sixth century. Then, as Qumranic documents show, the contacts continued: the Babylonian "Lunar Threes" were borrowed somewhere in the late second century в.с.е. Thus, one can create a chronological table of the Babylonian impact on Jewish astronomy (p. 247-249).

Ben-Dov's monograph builds upon the last thirty years of studies of Babylonian astronomy and the last twenty years of studies of the DSS (especially after the publication of the manuscripts from Cave 4 in 1991). This line of research was established by Neugebauer in 19791981 and followed by Albani and Gleßmer in the 1990s. Jonathan BenDov's new book shows that this line of inquiry is still very promising. In the 1950s, after the first publications of the Qumran discoveries, the scholarly community started to realise how much of early Christianity was Jewish. I believe it is now time to start realising how much Second Temple Judaism was Babylonian.

(43) Lourié, Review of A. Kulik, 3 Baruch. 